\title{
Comparison of Fault-Tolerant Operations for Permanent-Magnet Hybrid Brushless Motor Drive
}

\author{
Chunhua Liu, K. T. Chau, and Wenlong Li \\ Department of Electrical and Electronic Engineering, The University of Hong Kong, Hong Kong, China
}

\begin{abstract}
The permanent-magnet hybrid brushless (PMHB) motor adopts both DC field windings and PMs for excitation. It not only offers effective online flux control, but also flexible brushless DC (BLDC) or brushless AC (BLAC) operations. The key of this paper is to investigate two remedial strategies for fault-tolerant operations of the PMHB motor drive under open-circuit faults. First, by utilizing field excitation boosting, the reduced torque due to one phase loss can be remedied, the so-called remedial BLDC operation mode. Second, by reconstructing armature fields due to the healthy phase currents, the reduced torque can also be remedied, the so-called remedial BLAC operation mode. Finally, these two remedial operation modes are compared and verified by experimentation, hence confirming the validity of the proposed fault-tolerant PMHB motor drive.
\end{abstract}

Index Terms-Fault tolerance, flux control, hybrid motor, permanent-magnet (PM) motor, remedial operation.

\section{INTRODUCTION}

$\mathbf{I}$ N RECENT years, the development of fault-tolerant motor drives has received a great attention, focusing on the permanent-magnet (PM) brushless motor [1]-[4]. Very recently, a new kind of PM hybrid brushless (PMHB) motor has been proposed [5], [6]. It takes the definite advantage of flexible flux control, leading to offer wide-range constant-power operation and online efficiency optimization.

The purpose of this paper is to investigate two remedial strategies for fault-tolerant operation of the PMHB motor drive. First, by utilizing the merit of field excitation boosting, the reduced torque due to one phase loss can be remedied, the so-called remedial brushless DC (BLDC) operation. Second, by reconstructing armature fields due to the healthy phase currents, the reduced torque can also be remedied, the so-called remedial brushless AC (BLAC) operation. These two remedial operation modes will be discussed, compared and then verified by experimentation.

\section{PMHB MOTOR DRIVE}

Fig. 1 shows the proposed fault-tolerant PMHB motor drive, which consists of a three-phase PMHB motor, a three-phase full-bridge inverter (with only one phase sketched), and an H-bridge converter. The motor adopts a doubly-salient 36/24-pole outer-rotor double-layer-stator structure. It comprises 24 solid-iron salient poles in the outer rotor, 36 salient poles wound with armature windings in the outer-layer stator, and hybrid field excitations (PMs and DC field windings) in the inner-layer stator. In addition, an air-bridge in shunt with each PM has a role of amplifying the effect of flux control. The three-phase full-bridge inverter is used to achieve independent armature winding current control among phases, whereas the $\mathrm{H}$-bridge converter is used to control both magnitude and direction of the DC field winding current, hence regulating the airgap flux density.

Manuscript received October 26, 2009; revised January 28, 2010; accepted February 02, 2010. Current version published May 19, 2010. Corresponding author: C. Liu (e-mail: chualiu@eee.hku.hk).

Color versions of one or more of the figures in this paper are available online at http://ieeexplore.ieee.org.

Digital Object Identifier 10.1109/TMAG.2010.2042928

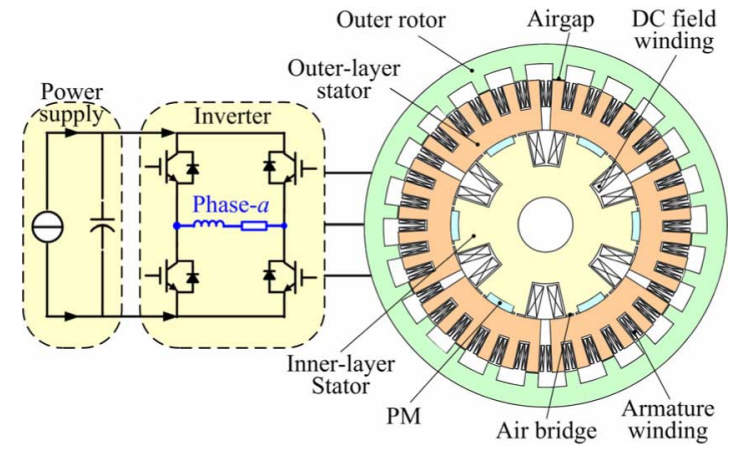

Fig. 1. Proposed PMHB motor drive.

The proposed motor drive possesses several distinct merits for fault-tolerant operation.

- The motor adopts concentrated armature windings in the outer-layer stator, which enables all phases having good magnetic independence. Also, the armature current controller adopts the full-bridge inverter topology, which offers good electrical isolation among phases. Hence, each phase of the motor drive can be regarded as a single module.

- All PMs are located in the inner-layer stator which is beneath the outer-layer stator with armature windings. Thus, they can be immune from accidental demagnetization by armature reaction, even under short-circuit fault.

- The outer-rotor inner-stator topology enhances the concept of electromechanical isolation, namely the medium between the electrical and mechanical parts is the airgap only.

- The solid outer rotor offers high mechanical robustness and direct-drive capability.

- With the use of controllable DC field current, the airgap flux density can readily be boosted up to remedy the loss torque during fault.

\section{REMEDIAL OPERATIONS}

In general, a motor drive mainly suffers from two kinds of faults, namely the open-circuit fault and short-circuit fault. For the proposed motor drive, the fault-tolerant operations will be focused on the open-circuit fault. In case the short-circuit fault that can be immediately isolated, it can be handled as an open- 


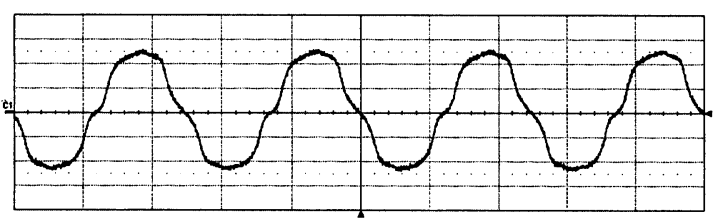

Fig. 2. Measured no-load EMF waveform (10 V/div, $5 \mathrm{~ms} / \mathrm{div})$.

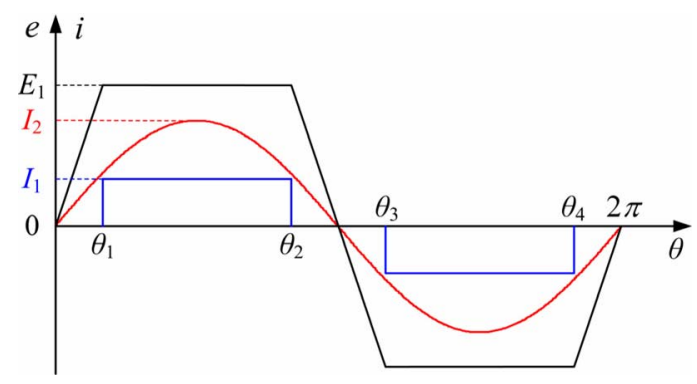

Fig. 3. Operation waveforms under BLDC and BLAC modes.

circuit fault. Other kinds of short-circuit faults such as due to terminal insulation problem need to be handled separately. The open-circuit fault occurs in the PMHB motor drive can be a winding open-circuit fault or a power device open-circuit fault, both resulting in disabling the faulty phase. Consequently, the motor drive needs to work at fault-tolerant operations.

\section{A. Normal BLDC and BLAC Operations}

According to the trapezoidal or sinusoidal shape of the no-load electromotive force (EMF) waveforms, the PM brushless motor can operate in the BLDC mode or BLAC mode [7]. Fig. 2 shows the measured no-load EMF of the PMHB motor at $200 \mathrm{rpm}$, where its shape is alike a trapezoid rather than a sinusoid. Thus, this PMHB motor usually operates in the BLDC mode with $120^{\circ}$ conduction angle. On the other hand, the motor can also work in the BLAC mode with $180^{\circ}$ conduction angle, but with torque pulsation. The corresponding operation modes are shown in Fig. 3, where $E_{1}$ is the amplitude of the trapezoidal EMF, $I_{1}$ and $I_{2}$ are the amplitudes of the rectangular and sinusoidal currents, and $\theta_{k=1,2,3,4}$ are the rotor positions for conduction in the BLDC mode.

The principle of operation of this PMHB motor is similar to other doubly-salient PM motors [8]. When the flux linkage increases with the rotor position, a positive armature current is applied with the conduction angle $120^{\circ}$ for BLDC operation or $180^{\circ}$ for BLAC operation, resulting in a positive torque. When the flux linkage decreases with the rotor position, a negative armature current is applied, also resulting in a positive torque. Thus, the whole cycle of flux linkage variation is utilized for torque production.

Under the normal BLDC mode, the armature current can be expressed as

$$
\begin{cases}i=I_{1} & \theta_{3} \leq \theta<\theta_{4} \\ i=-I_{1} & \theta_{3} \leq \theta<\theta_{4} \\ i=0 & 0 \leq \theta<\theta_{1}, \theta_{2} \leq \theta<\theta_{3},\end{cases}
$$

Ignoring the reluctance torque component, the electromagnetic torque $T_{1}$ under the BLDC mode can be written as

$$
T_{1}=\frac{P_{1}}{\omega}=\frac{3}{2 \pi \omega}\left(\int_{\theta_{1}}^{\theta_{2}} E_{1} I_{1} d \theta+\int_{\theta_{3}}^{\theta_{4}}\left(-E_{1}\right)\left(-I_{1}\right) d \theta\right)=\frac{2 E_{1} I_{1}}{\omega}
$$

where $P_{1}$ is the electromagnetic power under the BLDC mode, and $\omega$ is the angular speed.

Under the normal BLAC mode, the three-phase armature currents can be expressed as

$$
\left\{\begin{array}{l}
i_{\mathrm{a}}=I_{2} \cos \theta \\
i_{\mathrm{b}}=I_{2} \cos (\theta+2 \pi / 3) \\
i_{\mathrm{c}}=I_{2} \cos (\theta-2 \pi / 3) .
\end{array}\right.
$$

The electromagnetic torque $T_{2}$ under the BLAC mode is

$$
T_{2}=\frac{P_{2}}{\omega}=\frac{3}{2 \pi \omega} \int_{0}^{2 \pi}\left(E_{2} \sin \theta\right)\left(I_{2} \sin \theta\right) d \theta=\frac{3 E_{2} I_{2}}{2 \omega}
$$

where $P_{2}$ is the electromagnetic power under the BLAC mode, and $E_{2}$ is the amplitude of the fundamental component of the EMF. By applying Fourier analysis to Fig. 2, the basic relationship between $E_{1}$ and $E_{2}$ is given by

$$
E_{2}=1.42 E_{1}
$$

In order to enable these two operation modes having the equivalent output torque, the relationship between $I_{1}$ and $I_{2}$ can be deduced from (2), (4), and (5)

$$
I_{2}=0.94 I_{1}
$$

\section{B. Remedial BLDC Operation}

The PMHB motor can readily regulate the airgap flux density by simply tuning the DC field current. When it suffers from the open-circuit fault of phase- $a$, the motor can utilize its two healthy phases to operate in the remedial BLDC mode. The normal and remedial output torques can be written as

$$
\begin{aligned}
& T_{1}=C_{e} \Phi i_{p=a, b, c} \\
& T_{3}=C_{e} \Phi^{\prime} i_{p=b, c}
\end{aligned}
$$

where $\Phi$ and $\Phi^{\prime}$ are respectively the flux linkages under the normal and remedial BLDC modes, $i_{p=a, b, c}$ and $i_{p=b, c}$ are their normal and remedial currents, and $T_{3}$ is the electromagnetic torque during phase- $a$ loss. It is obvious that by strengthening the airgap flux density, $T_{3}$ can be boosted to $T_{1}$.

This strategy of field excitation boosting for remedial BLDC operation possesses the definite advantages of simple control and no intervention of armature current control. Nevertheless, there is a minor drawback that the torque pulsation may be enlarged due to the increase of flux linkage.

For this remedial BLDC operation, the armature winding copper loss is reduced while the field winding copper loss and iron loss are increased. Thus, its overall thermal condition is similar to that of normal operation. 


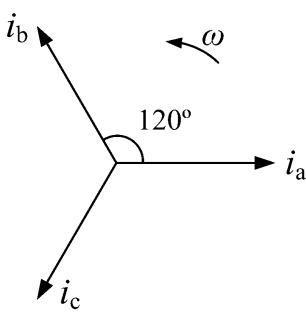

(a)

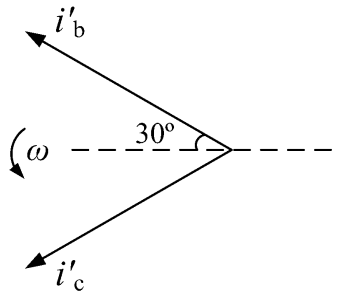

(b)
Fig. 4. Principle of remedial BLAC operation. (a) Three-phase currents before remediation. (b) Two-phase currents after remediation.

\section{Remedial BLAC Operation}

For PM motors, the electromagnetic property can be kept unchanged as long as the magnetomotive force (MMF) maintains constant. So, by reconstructing the amplitude and phase angle of the two healthy phase currents, the MMF of the PMHB motor can be kept unchanged.

Under the normal BLAC mode, the current phasors are depicted in Fig. 4(a). Since the three-phase currents are spatially displaced from each other by $120^{\circ}$, the rotating MMF can be expressed as the sum of MMFs generated by three-phase currents

$$
\begin{aligned}
\mathbf{M M F} & =\mathbf{M M F} \mathbf{F}_{\mathrm{a}}+\mathbf{M M F}_{\mathrm{b}}+\mathbf{M M F} \mathbf{F}_{\mathrm{c}} \\
& =N i_{\mathrm{a}}+\mathbf{a} N i_{\mathrm{b}}+\mathbf{a}^{2} N i_{\mathrm{c}}
\end{aligned}
$$

where $N$ is the number of turns of the armature winding per phase, and $\mathbf{a}=1 \angle-120^{\circ}$ stands for the displacement of threephase currents. By substituting (3) into (9), the MMF can be deduced as

$$
\mathbf{M M F}=\frac{3}{2} N I_{2}(\cos \theta+j \sin \theta)=\frac{3}{2} N I_{2} e^{j \theta} .
$$

Under the remedial BLAC mode, the phase- $a$ is under opencircuit so that the MMF can be reconstructed based on the two healthy phase currents

$$
\mathrm{MMF}^{\prime}=\mathrm{MMF}_{\mathrm{b}}^{\prime}+\mathrm{MMF}_{\mathrm{c}}{ }_{\mathrm{c}}=\mathbf{a} N i_{\mathrm{b}}^{\prime}+\mathbf{a}^{2} N i_{\mathrm{c}}^{\prime} .
$$

Hence, by equating (11) and (9), the remedial BLAC operation can produce the equivalent torque of the normal BLAC operation. Also, the remedial three-phase currents can be expressed as

$$
\left\{\begin{array}{l}
i_{\mathrm{a}}^{\prime}=0 \\
i_{\mathrm{b}}^{\prime}=\sqrt{3} I_{2} \cos (\theta+5 \pi / 6) \\
i_{\mathrm{c}}^{\prime}=\sqrt{3} I_{2} \cos (\theta-5 \pi / 6) .
\end{array}\right.
$$

The corresponding current phasors are depicted in Fig. 4(b). It can be observed that the remediation strategy is to lag the phase- $b$ current by $60^{\circ}$ and to advance the phase- $c$ current by $60^{\circ}$, while their current amplitudes are increased by $\sqrt{3}$.

For this remedial BLAC operation, the armature winding copper loss is increased while the field winding copper loss and iron loss are unchanged. Thus, its overall thermal condition is slightly higher than that of normal operation.

\section{RESULTS AND VERIFICATION}

The PMHB motor drive is prototyped and then mounted onto the test-bed for experimentation. The experimental set-up consists of the motor prototype, a power controller board (including the three-phase full-bridge inverter and H-bridge

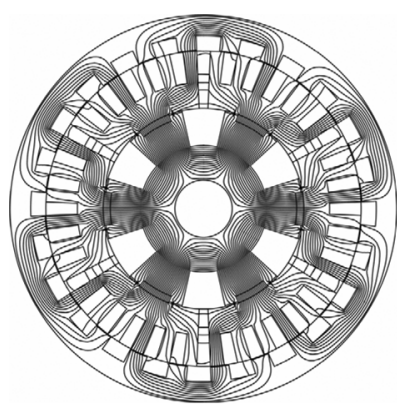

(a)

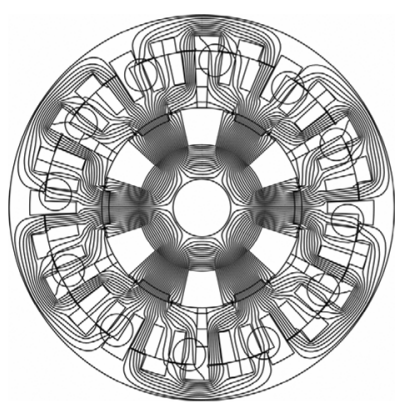

(b)
Fig. 5. Magnetic field distributions. (a) Normal operation. (b) Faulty operation.

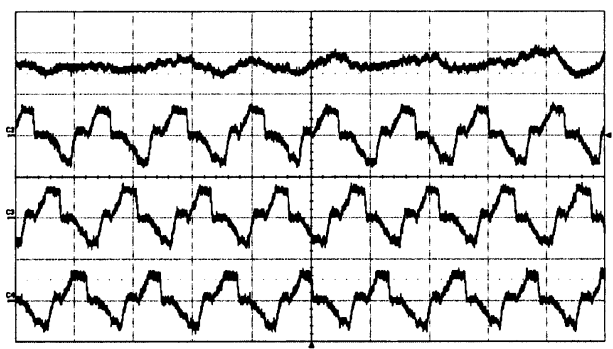

(a)



(b)

Fig. 6. Measured torque and current waveforms (4 Nm/div, $5 \mathrm{~A} / \mathrm{div}, 20 \mathrm{~ms} / \mathrm{div}$ ). (a) Normal BLDC operation. (b) Normal BLAC operation.

converter) to control the armature current and field current, a DC dynamometer to serve as mechanical load, a dynamic torque transducer to measure the instantaneous torque waveform, and three Hall-effect current transducers to measure the instantaneous three-phase current waveforms.

First, by using the time-stepping finite element method, the magnetic field distributions of the PMHB motor drive under the normal operation and one-phase open-circuit fault operation are depicted in Fig. 5. It can be observed that the normal operation pattern displays symmetrical and regular flux contours, whereas the faulty operation pattern exhibits asymmetrical and unbalanced flux contours (especially those circled areas).

Second, the normal BLDC and BLAC operations of the PMHB motor drive are performed by feeding rectangular and sinusoidal armature currents, respectively. Both operations are under the DC field current of 450 A-turn. Fig. 6 shows the measured output torque and three-phase armature current waveforms. As expected, the measured current waveforms are rectangular and sinusoidal under BLDC and BLAC operations, respectively. Their amplitudes well agree with the relationship given by (6). Moreover, it can be found that their average torques are nearly the same. Also, the torque pulsation under BLDC operation is less than that under BLAC operation, which is due to the fact that the EMF waveform is trapezoidal. 


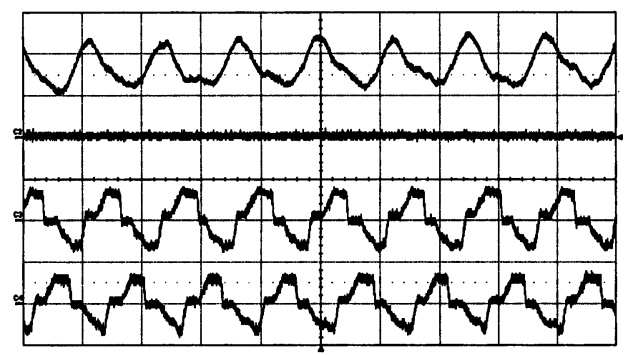

(a)

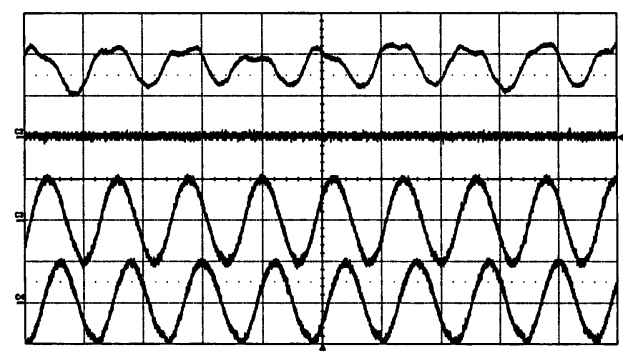

(b)

Fig. 7. Measured torque and current waveforms ( $4 \mathrm{Nm} / \mathrm{div}, 5 \mathrm{~A} / \mathrm{div}, 20 \mathrm{~ms} / \mathrm{div})$. (a) Remedial BLDC operation. (b) Remedial BLAC operation.

TABLE I

COMPARISON OF TORQUe PERFORMANCES

\begin{tabular}{lcccc}
\hline \hline $\begin{array}{l}\text { Operation } \\
\text { modes }\end{array}$ & $\begin{array}{c}\text { Average } \\
\text { torque }\end{array}$ & $\begin{array}{c}\text { Torque } \\
\text { ripple }\end{array}$ & $\begin{array}{c}\text { Phase } \\
\text { current }\end{array}$ & $\begin{array}{c}\text { Field } \\
\text { current }\end{array}$ \\
\hline Normal BLDC & $7.10 \mathrm{Nm}$ & $35.5 \%$ & $3 \mathrm{~A}$ & $450 \mathrm{~A}$-turn \\
Normal BLAC & $6.97 \mathrm{Nm}$ & $45.1 \%$ & $2.82 \mathrm{~A}$ & $450 \mathrm{~A}$-turn \\
Faulty BLDC & $4.95 \mathrm{Nm}$ & $75.7 \%$ & $3 \mathrm{~A}$ & $450 \mathrm{~A}$-turn \\
Remedial BLDC & $6.92 \mathrm{Nm}$ & $78.2 \%$ & $3 \mathrm{~A}$ & $750 \mathrm{~A}$-turn \\
Remedial BLAC & $6.96 \mathrm{Nm}$ & $68.1 \%$ & $4.88 \mathrm{~A}$ & $450 \mathrm{~A}$-turn \\
\hline \hline
\end{tabular}

It should be noted that the current waveforms in Fig. 6(a) is asymmetric. It is actually due to the classical design of doubly-salient structure which suffers from asymmetric flux linkage between the positive and negative cycles as well as among phases [8].

Third, after using the proposed remedial strategies of field excitation boosting and field reconstruction, the remedial BLDC and remedial BLAC operations are performed. Their measured output torque and three-phase armature current waveforms are shown in Fig. 7. For remedial BLDC operation, it can be seen that after the field current boosting to $750 \mathrm{~A}$-turn, the output torque can maintain virtually the same value as that of the normal operation. Also, the two healthy phase currents are still kept unchanged. On the other hand, for remedial BLAC operation, the output torque can also maintain nearly the same value under the same field current of 450 A-turn. It can also be observed that the two healthy phase currents are kept sinusoidal.

Finally, in order to quantitatively evaluate the normal, faulty, and remedial operations of the PMHB motor drive, the abovementioned experimental results are summarized in Table I in which the torque ripple factor $K_{T}$ is defined as

$$
K_{T}=\frac{T_{\max }-T_{\min }}{T_{\mathrm{av}}} \times 100 \%
$$

where $T_{\max }, T_{\min }$, and $T_{\mathrm{av}}$ are the maximum, minimum, and average output torques, respectively. It can be found that both the normal and remedial operations have almost the same output torque of $7.0 \mathrm{Nm}$, while their torque ripples are $35.5 \%-78.2 \%$ under the BLDC mode and $45.1 \%-68.1 \%$ under the BLAC mode. Without remediation, the faulty output torque is only $4.95 \mathrm{Nm}$, while the torque ripple is $75.7 \%$. Although the remedial BLDC operation has a slightly larger torque ripple than the remedial BLAC operation, the strategy of remedial BLDC operation is much simpler for implementation than that of remedial BLAC operation.

It should be noted that the torque ripples of the proposed motor drive under normal BLDC and BLAC operations are $35.5 \%$ and $45.1 \%$, respectively, which are mainly due to its doubly-salient structure. Actually, these torque ripples are already much lower than that of its doubly-salient counterpart, namely the SR motor drive.

As compared with the SR motor, the proposed motor can offer higher torque density because it has higher airgap flux density due to dual field excitation. On the contrary, it has lower torque density than the conventional PM brushless motor since it utilizes less PM volume.

\section{CONCLUSION}

In this paper, a new PMHB motor drive with high fault tolerance has been proposed and implemented. By using the field excitation boosting and field reconstruction strategies to handle the open-circuit fault, the motor drive can maintain the same output torque under faulty condition. The validity of the proposed remedial operations has been verified by experimental results. Also, it reveals that the strategy of remedial BLDC operation is much simpler for implementation than that of remedial BLAC operation, though its torque ripple is slightly larger.

\section{ACKNOWLEDGMENT}

This work was supported by a Grant (HKU 7105/07E) from the Research Grants Council, Hong Kong Special Administrator Region, China.

\section{REFERENCES}

[1] M. T. Abolhassani and H. A. Toliyat, "Fault tolerant permanent magnet motor drives for electric vehicles," in Proc. IEEE Int. Elec. Mach. Driv. Conf., May 2009, pp. 1146-1152.

[2] Y.-S. Jeong, S.-K. Sul, S. E. Schulz, and N. R. Patel, "Fault detection and fault-tolerant control of interior permanent-magnet motor drive system for electric vehicle," IEEE Trans. Ind. Appl., vol. 41, no. 1, pp. 46-51, Jan.-Feb. 2005

[3] B. C. Mecrow, A. G. Jack, J. A. Haylock, and J. Coles, "Fault-tolerant permanent magnet machine drives," IEE Proc.-Elec. Pow. Appl., vol. 143, no. 6, pp. 437-442, Nov. 1996.

[4] J. Wang, K. Atallah, and D. Howe, "Optimal torque control of faulttolerant permanent magnet brushless machines," IEEE Trans. Magn., vol. 39, no. 5, pp. 2962-2964, Sep. 2003.

[5] K. T. Chau, Y. B. Li, J. Z. Jiang, and C. Liu, "Design and analysis of a stator-doubly-fed doubly-salient permanent-magnet machine for automotive engines," IEEE Trans. Magn., vol. 42, no. 10, pp. 3470-3472, Oct. 2006.

[6] C. Liu, K. T. Chau, J. Z. Jiang, and L. Jian, "Design of a new outer-rotor permanent magnet hybrid machine for wind power generation," IEEE Trans. Magn., vol. 44, no. 6, pp. 1494-1497, Jun. 2008.

[7] K. T. Chau, C. C. Chan, and C. Liu, "Overview of permanent-magnet brushless drives for electric and hybrid electric vehicles," IEEE Trans. Ind. Electron., vol. 55, no. 6, pp. 2246-2257, Jun. 2008.

[8] Y. Gong, K. T. Chau, J. Z. Jiang, C. Yu, and W. Li, "Design of doubly salient permanent magnet motors with minimum torque ripple," IEEE Trans. Magn., vol. 45, no. 10, pp. 4704-4707, Oct. 2009. 